\title{
6 The Threat of Thinking Things into Existence
}

\author{
Kathrin Koslicki
}

According to Lynne Rudder Baker, our everyday world is populated, among other things, by what she calls intention-dependent objects ("ID objects"), i.e., objects whose existence depends on the propositional attitudes of intentional agents. ID objects, according to Baker, are objects that "could not exist in a world lacking beings with beliefs, desires, and intentions" (Baker, 2007, p. 11). ID objects instantiate intentiondependent properties ("ID properties"), i.e., "properties that cannot be instantiated in the absence of beings with beliefs, desires, and intentions; and similarly, for ID events and ID phenomena more generally" (ibid.). In Baker's view, it is impossible to make sense of the world, as we experience it, without taking on board the assumption that ID phenomena exist. And not only are ID phenomena part of our ordinary experience of the world, according to Baker, they are also "ineliminable from the explanatory apparatus of many of the special sciences"-e.g., "economics, sociology, political science, epidemiology, traffic science, and the like" (Baker, 2007, p. 46). As part of Baker's practical realist approach to metaphysics, she thus takes it to be "an obvious fact" that ID phenomena are real and that what exists, at least in part, depends on human activity:

A great deal of reality-though, of course, not all of it-depends on human activity. It does not follow that the only things that exist are the things that we have sortals for. There may well exist particles or biological natural kinds or future inventions that we have no sortals for. The claim that what there is depends on human activity is not 'incredible', nor is it an 'embarrassment'. It is an obvious fact.

(Baker, 2007, p. 47) ${ }^{1}$

Baker's claim that what exists, at least in part, depends on human activity opens her up to the concern, or so her critics have argued, that new

1 In the quoted passage, Baker is referring to objections raised against her account by Theodore Sider (2001, p. 155). 
objects and new kinds of object can apparently be "conjured" into existence, given her framework, simply by adopting new ways of thinking or speaking about already existing things (cf. Koslicki, 2018, Chapter 8). ${ }^{2}$ When Baker responds to a version of this objection launched against her account by Dean Zimmerman (2002), she proposes that we cannot simply think or speak things into existence for which "our conventions and practices do not have a place" (Baker, 2007, p. 44). In order for this response to be effective, however, we need to know more about how our conventions and practices support the creation of some ID objects and the kinds to which they belong, while disallowing the attempted creation of others. In this paper, I examine the effectiveness of Baker's response in addressing the challenges posed by the inclusion of ID objects, such as artifacts, in Baker's practical realist ontology.

\section{The Apparent Interest-Relativity of Existence}

Several of Baker's critics over the years have wondered whether, in setting out to characterize the world as we encounter and experience it, Baker does not in the end go too far in turning existence into a notion that is dependent on human interests. Theodore Sider, for example, raises an objection of this sort in his review of Baker (2000):

Baker's discussion of statues brings out one of the more implausible features of her ontology: what there is seems to depend on human interests. Everyone agrees humans can select certain objects from a pre-existing stock for their attention. For example, on the fourdimensional ontology I favor, a multitude of space-time worms exist regardless of human activity. Some fall under ordinary predicates: 'statue', 'lump', 'person', 'animal', and so on. But consider odd predicates we do not employ-for example, Eli Hirsch's 'in-car', which applies only to sums of stages of cars that are contained within a garage. The four-dimensionalist regards these odd objects as just as real as statues and persons; humans simply ignore them. But for

2 In Koslicki (2018, Chapter 8), I discuss this objection with a focus specifically on Baker's author-intention-based account of artifact essences, as defended for example in Baker $(2004,2007)$. For other author-intention-based approaches to artifact essences, see, e.g., Evnine (2016) and Thomasson (2003, 2007); although Baker, Evnine, and Thomasson disagree on the details, all three nevertheless share the general outlook that what it is to be a certain artifact or artifact kind is, directly or indirectly, determined by what an artifact's "original authors", i.e., its creators, inventors, makers, producers, designers, etc., intended to make when they set out to realize their creative intentions. The worry just raised, however, concerning the apparent interest-relativity of Baker's notion of existence, as it is understood for example by critics such as Theodore Sider and Dean Zimmerman, is broader in scope and applies to ID phenomena more generally. 
Baker, reality includes only the statues and lumps. (If Baker admits incars, and further admits objects corresponding to all possible trans-temporal tracing concepts, it can be argued that this would amount to admitting temporal stages after all, which she resists.) It is tempting to conclude that she thinks we create the world, that these continuants exist because we have concepts for them. Or is it a cosmic accident that reality just happens to contain objects whose histories match our ordinary concepts for tracing?

(Sider, 2002, pp. 47-48)

Sider finds it difficult to believe ("a cosmic accident"?) that there would be such a surprisingly seamless match between the concepts we, as humans, employ to trace objects through space and time and what in fact exists. Given Sider's own four-dimensionalist framework, he has the resources to assign the same ontological status to such apparent philosophical inventions as Eli Hirsch's "incars" (four-dimensional sums of stages consisting of cars while garaged) as he does to more commonly recognized entities, such as statues, animals, persons, and cars. Baker, in contrast, needs to be more selective and admit only the latter more commonly recognized entities, but not the former counterintuitive entities, into her three-dimensionalist ontology. This selectivity on Baker's part raises suspicions in Sider's mind that the apparently near-perfect correspondence between our human concepts and what is said to fall under them is in fact engineered into Baker's existence-concept to begin with by construing the latter notion in an interest-relative way. "It is tempting to conclude", so Sider surmises, "that [Baker] thinks we create the world, that these continuants exist because we have concepts for them" (ibid., p. 48).

A similar objection is voiced by Dean Zimmerman, toward the end of his critical discussion of Baker (2000). Zimmerman focuses in particular on Baker's conception of artifacts and is struck by the apparent ease with which new objects can be created, on Baker's view, by means of a mere shift in the ways in which we think or talk about already existing things:

Baker thinks we sometimes bring things into existence by thinking about them-at least, this follows from her view if objects can become artifacts (tools and works of art and monuments, for instance) simply by our thinking of them as such. A piece of conveniently shaped driftwood becomes a coffee table by being brushed off and brought into the house, a urinal becomes a sculpture when hung on a wall in a museum and given a title, a boulder becomes a boundary marker or memorial when it is up-ended and used for either purpose. But do we really believe that anything new comes into existence when we do such things? One problem is that these acts are 
on a spectrum with creative activities that seem really to result in something new; and that the idea of a sharp cutoff somewhere on the spectrum is both hard to believe in, yet necessary if we do not want to allow for things that only sort-of-exist-another difficult notion, for surely if there are such things, well, then there they are, existing after all!

(Zimmerman, 2002, pp. 333-334)

Why, so Zimmerman asks, should we follow Baker in believing that our thought and talk can succeed in creating new objects out of previously existing things in some cases but not in other cases to which they are otherwise so similar? Suppose, for example, that a shift in our verbal or nonverbal attitude can result in the creation of new objects from previously existing things in the sorts of case Zimmerman cites: conveniently shaped pieces of driftwood giving rise to coffee tables; a urinal being transformed into a sculpture; and a boulder serving as the basis for the creation of a boundary marker or memorial. Then, why does it strike us as counterintuitive in other cases to suppose that a new object is created from previously existing things as a result of a shift in our attitudes or behaviors? For example, we do not commonly suppose that a new object, the president of the United States, comes into existence when an individual human being begins to serve in a certain role (e.g., as commander-in-chief of the armed forces, etc.). If we did posit that the president of the United States is a distinct object that merely spatiotemporally coincides with the human being who occupies this office, the object in question would have properties that would no doubt strike us as unusual and surprising: e.g., the president of the United States would have the ability to endure for hundreds of years and outlast each individual human office-holder; on certain occasions (e.g., during the inauguration), this object would have the ability to jump discontinuously in an instant from one place to another by several feet; and so forth. However, as Zimmerman notes, similar properties also seem to apply to objects in cases in which Baker might be less reluctant to admit that a shift in the ways in which we relate to previously existing things has the power to create new objects. For example, suppose Baker is willing to allow that there is such a thing as a train-line, e.g., the "Orange Blossom Special", an object that is numerically distinct from but spatiotemporally coincident with certain train cars, engines, engineers, etc. Like the president of the United States, the "Orange Blossom Special" also seems to have the ability to outlast the particular train cars, engines, engineers, etc., with which it coincides at each particular time at which the trainline exists; or the ability to jump discontinuously in an instant from one set of tracks to another, all the while apparently persisting as the very same train-line; and so forth. If Baker is willing to accept such things as train-lines as part of her ontology, then why not also United States 


\section{Kathrin Koslicki}

presidents? Where and how, in the spectrum of cases Zimmerman discusses, does Baker draw the line between cases in which new objects are created and cases in which we merely come to talk, think, or otherwise behave differently toward already existing things? Zimmerman regards it as extremely unlikely that a systematic cut-off point could be found by which to distinguish cases of genuine creation from cases in which we merely adopt different verbal or nonverbal attitudes toward already existing things. If, however, no such principled dividing line is forthcoming, then Zimmerman, like Sider, wonders whether Baker's approach merely reflects the way in which our human minds represent the world, rather than yielding a genuinely realist metaphysics, as advertised. ${ }^{3}$

\section{Baker's Replies to her Critics}

In Chapter 2 ("The Reality of Ordinary Things") of The Metaphysics of Everyday Life, Baker replies to the concerns cited in the previous section (Baker, 2007, pp. 43-47). ${ }^{4}$ In her response, Baker distinguishes between several different types of case that, in her view, need to be treated differently. In the first type of case, an attempt is made to create a new object that (if the attempt is successful) would belong to an already recognized primary kind. In the second type of case, an attempt is made to create a new object that (if the attempt is successful) would result not just in a new member of an already existing kind but also in a completely new kind of object, i.e., an object whose primary kind had not previously been recognized in any fashion. In the third type of case, an attempt is made to create a new object that (if the attempt is successful) would belong to a kind that was previously recognized but not as a primary kind.

Baker conceives of the distinction between primary kinds and nonprimary kinds as follows. For everything, $\mathrm{x}$, that exists, in Baker's view, we can ask the question, "What is $\mathrm{x}$ most fundamentally?", and the answer to this question will yield x's primary kind (Baker, 2007, pp. 9-10). An entity's primary kind is intimately tied to the entity's persistence conditions and both are essential to it. To illustrate, suppose $\mathrm{x}$ is both a person and a teacher, but person, and not teacher, is x's primary kind; then $\mathrm{x}$ is essentially a person but only contingently a teacher. Furthermore, if $\mathrm{x}$ 's primary kind is the kind person, then $\mathrm{x}$ is capable of surviving the

3 Insofar as Zimmerman's objection raises questions concerning vagueness, the reader is referred to Baker (2007, Chapter 6) for a defense of the view that there is vagueness in reality, and not just in our semantic, conceptual, or epistemic ways of representing reality. For the purposes of the present discussion, however, we will leave questions concerning vagueness to one side.

4 See also Baker (2002, pp. 47-49), for an earlier discussion of the criticisms raised in Sider (2002) and Zimmerman (2002). 
sorts of change through which persons can persist and $\mathrm{x}$ will cease to exist under the sorts of condition under which persons cease to exist.

It is a unique feature of Baker's "Constitution View" that one and the same kind property, e.g., being a statue, need not be had essentially or nonderivatively by everything that has it at all, since the kind property in question need not be the primary kind property of all those objects that have it. For example, Michelangelo's David is essentially or nonderivatively a statue; being a statue is David's primary kind property. But Piece, the numerically distinct piece of marble that is spatiotemporally coincident with David, is also a statue, on Baker's view, but it is so only contingently or derivatively, viz., by virtue of being related to David in a particularly intimate fashion; being a statue is a kind property instantiated by Piece, but Piece's primary kind property is being a piece of marble and not being a statue. This kind of situation, in Baker's view, is characteristic of the relationship objects bear to one another when one object (viz., Piece) constitutes another (viz., David). While some kind properties can play the dual role just noted (of being able to function both as primary kind properties for some objects, and as non-primary kind properties for other objects intimately related to the first), other kind properties (e.g., being a teacher) only ever function as non-primary kind properties for those objects that have them: nothing that is a teacher is a teacher essentially; and being a teacher does not determine the persistence conditions of those objects that instantiate this kind property.

\subsection{Creating New Objects Belonging to Existing Primary Kinds}

The examples brought up by Zimmerman in the passage cited above serve as illustrations of Baker's first case. Suppose that an agent sets out to create a new object (e.g., a coffee table, sculpture, boundary marker, or memorial) from an already existing thing (e.g., a piece of driftwood, urinal, or boulder); and suppose further that the act of creation is successful. In this case, the new object that is created would belong to an already recognized primary kind (viz., the primary kind, coffee table, sculpture, boundary marker, or memorial). Thus, while a successful act of creation in the first case adds a new entry to the inventory of already existing objects, the act in question does not lead to the expansion of our repertoire of previously recognized primary kind properties.

Even in this type of case, however, Baker insists that Zimmerman's treatment leaves out some important considerations and, as a result, makes it seem as though the creation of new objects is an easier affair than it really turns out to be on Baker's account. For even in a case in which a coffee table, say, is brought into existence from a conveniently shaped piece of driftwood, Baker notes that more is required than merely 


\section{Kathrin Koslicki}

that the piece of driftwood is "brushed off and brought into the house" (Zimmerman, 2002, p. 333), even when these actions (neither of which, of course, falls under the category of thought or talk) are combined with other changes in the verbal or nonverbal behaviors and attitudes held by certain agents who interact with the piece of driftwood in question. In addition, Baker points out, certain "table-favorable circumstances" must also obtain in order for a conveniently shaped piece of driftwood to give rise to a new object, a coffee table, with which it is spatiotemporally coincident but not identical. According to Baker's usage, for any given primary kind property, G, the phrase "G-favorable circumstances" denotes the total background conditions that must be in place in order for something to have G; the presence of G-favorable circumstances is necessary, but not sufficient, for the instantiation of $G$ by a suitable object (cf. Baker, 1999, p. 149). In the kind of case before us, the "tablefavorable circumstances", in Baker's view, would include, for example, practices and conventions governing our interactions with tables that are already in place; it is only in the context of such already established ways of engaging with objects of the kind in question that an agent is able to create a new member of the already existing primary kind, coffee table, by talking, thinking, and otherwise behaving differently toward a suitable thing that already exists, e.g., a conveniently shaped piece of driftwood. Although Baker allows that our thought and talk can in certain cases make an essential contribution to the creation of new objects from already existing things, these contributing factors by themselves are nevertheless not sufficient for the creation of a new member of an already existing kind; rather, they must work in conjunction with other conditions, e.g., established ways of interacting with objects of the kind in question, if an agent's attempt at creating a new member of an existing primary kind is to be successful.

\subsection{Creating New Objects Belonging to New Primary Kinds}

The second type of case is meant to illustrate a more radical possibility: an act of creation that (if the act is successful) would not simply bring into existence a new member of an already existing kind, but rather result in the creation of a whole new primary kind. To illustrate this type of possibility, Baker imagines the following scenario:

... [O]ur practices and conventions, as well as our intentions, are what make one piece of driftwood constitute a table, and another piece of driftwood constitute a piece of art. If I saw a piece of driftwood and made up the word 'bonangle' on the spot, and thought to myself, 'It would be nice if the world contained bonangles; I hereby make that piece of driftwood a bonangle', I would not have brought into existence a new thing, a bonangle; our conventions and 
practices do not have a place for bonangles. It is not just thinking that brings things into existence.

(Baker, 2007, pp. 43-44)

In this type of scenario, again contrary to what Zimmerman's objections might have us believe, merely thinking or speaking in a new way about an already existing thing, e.g., a piece of driftwood, is not enough, on Baker's account, to bring into existence a new kind of object, a bonangle. Rather, as in the previous case, Baker crucially appeals to the role of our existing practices and conventions in underwriting the would-be creative powers of intentional agents and their verbal or nonverbal behavior. In this case, however, unlike the previous one, our established practices and conventions, in her view, do not support the imagined attempt at creating a new kind of object, a bonangle, from an already existing thing, e.g., a piece of driftwood. Rather, the attempted act of creation in question misfires and neither a new object nor a new kind of object results from the supposed application of the newly invented word, "bonangle", to an already existing thing. ${ }^{5}$

It is important to note in this connection that there is no general prohibition, in Baker's view, against the creation of new primary kind properties. Thus, the fact that we cannot create a novel type of object, a bonangle, by applying the new word, "bonangle", to an already existing thing, e.g., a piece of driftwood, is not due to the fact that there are, as of yet, no established practices and conventions that govern specifically our interactions with bonangles. The adoption of such a principle would make it impossible ever to enlarge our existing pool of primary kind properties, e.g., by inventing a new kind of object or by otherwise adding a previously unrecognized type of thing to those with which we are already familiar. But Baker explicitly acknowledges that our supply of primary kind properties must be taken to be open-ended and that, for this reason, no exhaustive list of what there is could ever be provided:

5 Although Baker does not explicitly mention such worries here, we might also wonder, given existing constraints governing word-creation, whether the creative failure illustrated in Baker's imagined scenario affects not only the attempt to call into existence a new type of object, a bonangle, but also the attempt to create a new word, "bonangle", by uttering a string of sounds and simply declaring it to be a new word, presumably one that (if the creative attempt is successful) now belongs to the English language. I will not in the present context investigate further what else might be required in order for intentional agents to succeed in adding new words to their language. However, Baker's general response to Zimmerman's objection may nevertheless apply to this case as well, assuming that, even in the case of words themselves, it is questionable whether a new member of an already existing primary kind can be established simply by uttering a certain string of sounds, accompanied by certain thoughts, intentions, and other propositional attitudes on the part of an individual speaker on a particular occasion. 


\section{Kathrin Koslicki}

Since a theory of primary kinds would be tantamount to a theory of everything, however, it is not surprising (although still regrettable) that I do not have one. And since we are constantly bringing into existence new kinds of things-from airliners to personal computersthere is no saying in advance exactly what the primary kinds will turn out to be.

(Baker, 2000, p. 41)

Thus, the deficiency in the imagined scenario does not turn on the fact that there are, as of yet, no established practices and conventions that govern our interactions specifically with bonangles. Rather, what Baker presumably has in mind is that some other shortcoming applies in this particular instance that prevents our established ways of interacting with other kinds of object from underwriting the imagined attempt at simultaneously creating both a new object and a new primary kind. We will return to the question of what this shortcoming might be in Section 3.2 below. Whatever its exact nature, though, it is clear that Baker does not think the same deficiency afflicts all instances of the second type of case in which intentional agents attempt to create an entirely new kind of object from scratch: for there are, in Baker's view, successful instances in which our existing practices and conventions do support the creation of an object belonging to a new primary kind (e.g., airliner or personal computer) that, prior to its creation, is also not yet governed by its own specific set of practices and conventions. As in the first type of case, however, Baker emphasizes that more is needed in order for a successful act of creation of the second type to get off the ground besides new ways of thinking or talking about already existing things; in both cases, the relevant background conditions must also already be in place in order for the creative act in question to be successful.

\subsection{Creating New Objects by Transforming Non-Primary Kinds into Primary Kinds}

To illustrate the third type of case, Baker takes up the challenge mentioned by Zimmerman and asks whether (and, if so, under what conditions) a new object belonging to a new primary kind could be added to our existing inventory by transforming a previously recognized "mere" non-primary kind, e.g., president of the United States, into a primary kind. To illustrate, if it were possible for such a transformation to take place, then the event to which we now refer as "the assassination of John F. Kennedy" would have to be reconceptualized as follows: as a result of what happened on November 22, 1963, in Dallas, Texas, the very same United States president, who up until that point was known as "John F. Kennedy" continues to exist, but now under a new name, viz., "Lyndon B. Johnson". Though the shots fired during the motorcade on that day 
do affect the overall count of persons, the very same United States president exists both at the beginning and at the end of the day, at first (until 1:00 pm) spatiotemporally coincident with one person, John F. Kennedy, and subsequently (at 2:38 pm), after a short break, with a distinct person, Lyndon B. Johnson.

What happens during the intervening period of time, which lasts one hour and thirty-eight minutes, between the events currently known as "John F. Kennedy's death" at 1:00 pm and "Lyndon B. Johnson's inauguration" at 2:38 pm? There are different options, depending on what sorts of object United States presidents turn out to be, under the new rules, and how exactly they persist through time. According to one option, such objects have the ability to exist in a "gappy" or intermittent fashion: given this option, the very same United States president goes out of existence on November 22, 1963 at 1:00 pm and then comes back into existence a short while later on the same day at 2:38 pm. Given this conception, United States presidents might be thought of as, in some respects, similar to artifacts (e.g., trumpets, bicycles, or watches) that can be disassembled and then reassembled, assuming that the very same artifact ceases to exist, when disassembled, and comes back into existence, when reassembled. Alternatively, United States presidents might be able to take on different "modes" of existence, depending on whether a person is or is not spatiotemporally coincident with them: given this option, the very same United States president goes from being, so to speak, "personified" to being "non-personified" and back again, without ceasing to exist. Given this second option, United States presidents might be compared to human souls, on a Thomistic conception, according to which they can switch, between death and resurrection, from existing in an "embodied" state to existing in a "disembodied" state and back again, without ceasing to exist. Either way, the persistence conditions governing objects that are fundamentally, i.e., essentially and nonderivatively, United States presidents and only contingently or derivatively persons diverge quite dramatically from those governing objects that are fundamentally, i.e., essentially and nonderivatively, persons, but only contingently or derivatively United States presidents.

Is it possible and, if so, what sorts of change would have to take place, Baker asks, in order to bring about a transformation like that just imagined in which the kind, president of the United States, goes from being a non-primary kind to being a primary kind? In true pragmatist fashion, Baker cannot rule out with absolute certainty that such a transformation would ever occur; she does, however, regard it as extremely unlikely for the following reasons (cf. Baker, 2007, p. 45). First, Baker observes, in other cases in which a new primary kind (e.g., printing press or passport) is brought into existence as a result of actions taken by intentional agents, we notice that the creative acts in question do not follow the pattern envisioned in the third type of case in which an existing 


\section{Kathrin Koslicki}

non-primary kind is allegedly transformed into a primary kind. Rather, in these instances, a new primary kind is created from scratch (i.e., as outlined in the second type of case) without having previously existed as a non-primary kind. Furthermore, in order for president of the United States to go from being a non-primary to being a primary kind, corresponding changes would have to take place in our established ways of relating to the United States presidency, in order for the imagined transition to come about. And while perhaps not outright impossible, so Baker argues, we nevertheless have no reason to expect, given the kinds of creatures we are, that the practices and conventions in which the institution of the United States presidency is currently embedded would ever evolve in such a way as to accommodate the transformation in question. Elaborating on this second point, Baker remarks as follows:

In the second place, it is difficult to imagine any human interest that would lead to conventions making president a primary kind. Our conventions are based on our interests, and I cannot imagine any human interest that would lead to conventions that would make president to be a primary kind. We choose what interests to have only within a limited range. We cannot just change our interests at will. I don't think that we could just decide to change our general interest in having shelter, or in being treated with dignity. I agree with the evolutionary psychologists to this extent: Our interests are not wholly malleable. So, I doubt that we could come to regard president as a primary kind. In that case, no change in the way that we talk would bring it about that president is a primary kind.

(Baker, 2007, p. 45)

In Baker's view, the practices and conventions governing our ways of interacting with objects are in some way determined by human interests. And while our interests allow for some degree of malleability in how we engage with the world around us, there are nevertheless limits to our ability to modify our established ways of interacting with objects or adopt a different set of practices and conventions from those that are already in place. Given this picture, then, Baker regards it as unrealistic to suppose that our existing practices and conventions would change in a way required by the imagined transformation of the kind, president of the United States, from being a non-primary kind to being a primary kind.

In sum, with respect to all three types of cases just considered, Baker takes herself to have shown that, despite Zimmerman's charges to the contrary, her approach yields the right results after all. Whether agents attempt to create new objects belonging to existing primary kinds (as in the first case) or new primary kinds (as in the second and third case), more is required, on Baker's account, for an attempted act of creation to 
be successful than a mere shift in the way in which we talk or think about existing things. When Zimmerman speaks of "a powerful resistance to the idea that changes in our ways of talking about things, even coupled with simple changes in some of our nonverbal reactions to things, could by themselves bring any concrete physical object into existence" (Zimmerman, 2002, p. 335), Baker counters that

... [A]lthough I do hold that thought and talk make an essential contribution to the existence of certain objects, I do not hold that thought and talk alone bring into existence any physical objects: conventions, practices, and preexisting materials are also required. So, on my view, what brings concrete things into existence is not just 'ways of talking about things, even coupled with simple changes in some of our nonverbal reactions to things'. I do not think that we just conjure up new concrete physical objects of an afternoon.

(Baker, 2007, p. 46)

As Baker notes here, the creation of new concrete physical objects by intentional agents requires the presence of at least the following three conditions: (i) suitable preexisting materials; (ii) the contributions of intentional agents (e.g., new ways of talking, thinking, or otherwise interacting with existing things); and (iii) practices and conventions providing the needed background support for an intentional agent's creative act. It is only when all three of these factors act in concert that intentional agents can succeed in creating new concrete physical objects belonging to an existing or a new primary kind. ${ }^{6}$

\section{Baker's Appeal to Practices and Conventions}

Baker's defense against her critics relies heavily on the role of practices and conventions in underwriting efforts by intentional agents to expand our existing repertoire of objects and the primary kinds to which they belong. In this section, we examine in more detail how Baker's appeal to established ways of interacting with objects is intended to diffuse the charge of antirealism mounted against her approach by commentators such as Sider and Zimmerman. Our discussion will again proceed by considering each of the three cases described in Section 2 separately. ${ }^{7}$

6 As noted here, when discussing the possible creation of new objects or new primary kinds by intentional agents, Baker and her critics have in mind specifically concrete physical objects and the primary kinds to which they belong. For the sake of simplicity, when I speak of "objects", in what follows, I can be taken to mean "concrete physical objects", unless otherwise noted.

7 When Baker appeals to the role of practices and conventions in underwriting attempts by intentional agents to create new objects or new primary kinds, she does not further 


\section{Kathrin Koslicki}

\subsection{Artifact Creation}

How, in Baker's view, do our existing practices and conventions underwrite and constrain attempts by intentional agents to create new objects belonging to already recognized primary kinds? Since many of the illustrations used above concern artifacts, we will respond to the question just posed by (briefly) consulting Baker's understanding of what it takes for an artifact to come into existence (see Baker, 2004 \& Baker, 2007, Chapter 3). Baker's theory of artifacts is primarily directed toward what she calls "technical artifacts", a subclass of artifacts that are "the material products of our endeavors to attain practical goals": technical artifacts, in Baker's view, are "intentionally made to serve a given purpose" (Baker, 2007, p. 49). It is part of the essence of technical artifacts, i.e., entailed by the primary kind to which they belong, that they have intended proper functions, i.e., "proper functions that they are (intentionally) designed and produced to perform (whether they perform their proper functions or not)" (Baker, 2007, p. 51). The notion of an intended proper function introduces normativity into the mix, which in turn makes room for the possibility of malfunction, i.e., the idea that a technical artifact may be unable to perform the intended proper function it is supposed to carry out (ibid.). ${ }^{8}$

To illustrate Baker's conception of artifact creation, let us consider (as Baker does) the example of a boat ("Boat") that, once it comes into existence, is constituted by an aggregate ("Agg") of planks and nails. ${ }^{9}$ The

elaborate on how we are to think of practices and conventions in this context. According to David Lewis' classic Humean account (Lewis, 1969), social conventions are regularities (i.e., systems of intentions, preferences, and expectations) characterizing agents who find themselves confronted by a coordination problem of some sort (i.e., a situation in which there is more than one mutually beneficial way for agents to coordinate their actions). But not everyone agrees that social conventions should be understood in the Lewisian way (see, for example, Marmor, 2009; Gilbert, 1989). A helpful survey of the literature on convention can be found in Rescorla (2019). The nature of practices in general is discussed, for example, in Theodore Schatzki's "Introduction" in Schatzki, Knorr Cetina, and von Savigny (2001). For the purposes at hand, I assume that Baker regards a practice as something more elaborate than an individual action that is performed by an individual agent on a particular occasion. Rather, Baker seems to view practices as ways of organizing individual actions into systems of some sort that are governed by corresponding sets of conventions. Section 3.1 considers in more detail how Baker envisions processes of artifact creation as practices governed by corresponding sets of conventions.

8 In what follows, I will refer to technical artifacts simply as "artifacts".

9 Aggregates, according to Baker, are just mereological sums, as they are conceived of by standard or classical extensional merelogy; that is, the existence and identity of an aggregate turns on nothing more than the existence and identity of the objects composing it. An aggregate that consists, for example, of planks and nails belongs to a "hybrid" primary kind, plank/nail, "by courtesy", i.e., by virtue of the fact that it is composed of objects that belong to the primary kinds, plank and nail. In order for 
process of constructing Boat from Agg is governed by four conditions that Baker takes to be necessary and sufficient for something's being an artifact (modified here to fit the particular case under consideration): (1) Boat is constructed by one or more builders (including designers, executors of design, or others who are involved with Boat's construction); (2) Boat's primary kind, boat, is determined in part by the intentions of its builders; (3) Boat's existence depends on the intentions of its builders and the execution of these intentions; and (4) Boat is constituted by Agg, an aggregate the builders have arranged or selected to serve the proper function entailed by Boat's primary kind, viz., to enable aquatic transportation. In order to serve the purpose at hand, Agg must be "appropriate", i.e., suitable for the construction of an artifact, viz., Boat, whose intended proper function is to enable aquatic transportation. ${ }^{10}$ In addition, Baker's definition of "constitution" requires, among other things, that, in order for Agg to constitute Boat, Agg must be in "boat-favorable conditions" (cf. Section 3.1 above):

The boat-favorable circumstances concern the relations between an appropriate aggregate for boats, designers and/or builders. For example: (a) the aggregate must be in the presence of one or more persons who know how to build a boat from the items in the aggregate, and who either intend to build a boat from the items in the aggregate or whose activity is directed by someone who intends to have a boat built from the items in the aggregate; (b) the items in the aggregate must be manipulated by such persons (either manually or by machine) in ways that execute their productive intentions or of those directing the persons; (c) the result of the manipulation must satisfy the productive intentions of the persons.

(Baker, 2007, p. 54)

As Baker notes in this passage, the "boat-favorable circumstances" that must be in place in order to underwrite Boat's construction from Agg

an aggregate to belong to the hybrid primary kind, plank/nail, the x's composing the aggregate must either belong to the primary kind, plank, or the primary kind, nail (Baker, 2007, p. 50). Since all it takes for Agg to exist is for the planks and nails composing Agg to exist, Agg already exists prior to Boat's construction; and assuming that no planks or nails cease to exist during the process of constructing Boat, Agg will continue to exist after Boat's creation, at which point Agg comes to constitute Boat, provided that the conditions contained in Baker's definition of "constitution" are satisfied by the relation that obtains between Boat and Agg.

10 For a general formulation of (A1)-(A4), the four conditions Baker takes to be necessary and sufficient for something's being an artifact, as well as a more detailed statement of the two conditions, (i) and (ii), for the "appropriateness" of an aggregate for the purpose of constituting an artifact with a certain intended proper function, see Baker (2007, pp. 52-53). 


\section{Kathrin Koslicki}

include requirements concerning the know-how as well as the skillful execution of the relevant sorts of productive intention on the part of the builders or others involved in the process of constructing Boat from Agg. And although Baker does not explicitly say so here, we can safely assume that the requirements she cites in (a) $-(\mathrm{c})$ are exactly what she has in mind when she speaks elsewhere of "practices and conventions" as providing the needed background support for the successful creation of objects by intentional agents. In this case, presumably, the relevant practice is that of boat construction and the conventions in question are those governing the practice of boat construction. The process of constructing Boat from Agg thus fits Baker's three conditions, outlined above (cf. Section 2.3), according to which the successful creation of ID objects must proceed (i) from preexisting materials; (ii) by way of the contributions of intentional agents; (iii) with the right background support provided by existing practices and conventions. For, first, Boat's construction proceeds from Agg, an "appropriate" aggregate consisting of preexisting materials that are suitable for the purpose at hand, viz., the construction of Boat, an artifact whose intended proper function is to enable aquatic transportation. Second, Boat's construction from Agg proceeds by way of contributions from intentional agents, viz., the builders, designers, and others involved with the construction of Boat from Agg, who skillfully manipulate these preexisting materials and execute their know-how for the purposes of realizing their productive intentions. And, third, Boat's construction from Agg takes place within the context of the existing practice of boat construction as well as the conventions governing this practice, which help to determine what sorts of skill and know-how are expected from agents who wish to participate in the practice in question by realizing their productive intentions to build a boat from suitable preexisting materials. ${ }^{11}$

This illustration of how the construction of Boat from Agg is embedded within the established practice of boat construction and the conventions governing it certainly helps to bring home the point that the

11 Once Boat has come into existence, then a different set of practices and conventions takes over from those governing boat construction; for, at that point, the task at hand is no longer that of creating a new artifact with the intended proper function of aquatic transportation from preexisting materials. Rather, once the productive intention to build Boat from Agg has been successfully executed, the relevant practices and conventions governing an intentional agent's interaction with Boat concern the competent use of an artifact whose intended proper function is aquatic transportation. The relevant intentional agents interacting with Boat are then no longer builders, designers, etc., but rather those who competently operate, maintain, and use Boat for its intended purpose, in circumstances that are compatible with its intended purpose. For further elucidation, see Baker's remarks on how to demarcate genuine cases of malfunction from other circumstances in which artifacts fail to perform their intended proper functions, in Baker (2007, pp. 55-58) and Baker (2009). 
creation of new objects belonging to existing primary kinds, at least in some cases, can be quite a demanding affair, given Baker's requirements. For, under normal circumstances, a new artifact that can be trusted to transport people and goods safely across bodies of water cannot be created merely by uttering certain words or thinking certain thoughts about preexisting things, such as planks, nails, and whatever else is involved in the construction of a boat. At the same time, though, a case like that before us involving Boat's construction from Agg will not ultimately put to rest concerns voiced by critics such as Sider and Zimmerman, who worry that, deep down, the notion of existence employed by Baker's account is nevertheless objectionably interest-relative. For Baker's appeal, in this case, to established practices and conventions of course presupposes that we have already come to terms with the inclusion of boats, planks, nails, and other apparently intention-dependent objects in our ontology; and the same will be true of any other instance of the first type of case in which a new object belonging to an already recognized primary kind comes into existence as result of an intentional agent's creative act. It is thus vital to turn to the second and third type of case involving the alleged creation of new kinds of object to see whether Baker's reliance on practices and conventions, in cases in which the existence of the primary kind in question is not already presupposed, can help firm up the boundary between successful and unsuccessful attempts by intentional agents to realize their productive intentions.

\subsection{Primary Kind Creation}

In Section 2.2, we discussed a failed instance of the second type of case in which an intentional agent simultaneously attempts to create a new object, a bonangle, and a new primary kind, bonangle, by applying the newly invented word, "bonangle", to an already existing thing, a piece of driftwood. In this instance, Baker regards the attempted act of creation as unsuccessful, since "our conventions and practices do not have a place for bonangles" (Baker, 2007, p. 44). Although the bonangle-scenario seems to meet the first and second condition Baker places on successful attempts by intentional agents to create new objects, the third condition in this case is not satisfied: the attempted creation of a bonangle, or so we may assume, proceeds (i) from suitable preexisting materials, viz., a piece of driftwood; ${ }^{12}$ and (ii) with the contribution of an intentional

12 Whether pieces of driftwood are indeed "suitable" for the creation of bonangles (if they were to exist) is difficult to say, since bonangles do not in fact exist and we have, as I am about to suggest, very little information as to what sorts of thing bonangles would be, if they existed. However, since Baker's emphasis is on the lack of support from existing practices and conventions, rather than on the inadequacy of pieces of driftwood for the purposes of constituting bonangles, I am assuming that the scenario 
agent, who applies the new word, "bonangle", to the piece of driftwood; but (iii) our existing practices and conventions do not provide the needed background support to underwrite the attempted creation of a new primary kind. ${ }^{13}$

Why is it that the introduction of a new primary kind, bonangle, is not supported by our existing practices and conventions? It is not entirely clear how, given Baker's views, this question ought to be answered, since the imagined scenario, as it stands, is quite under-described and we therefore do not have much to go on in our attempt to understand what a bonangle would be, if one of them had come into existence, and why our existing practices and conventions might block an intentional agent's attempt to create such entities. We can at least gather from what Baker does say, however, that, if the imagined creative act had been successful, the bonangle that would have come into existence would have been, first, a concrete physical object and, second, an ID object. For, first, if the attempted act of creation in question had been successful, the newly created bonangle would have been constituted by (and hence numerically distinct from but spatiotemporally coincident with) a piece of driftwood. And, second, since the act of applying the word "bonangle" to the piece of driftwood seems to play a crucial role in the attempted creation of a bonangle, we can assume that the bonangle that would have come into existence (had the creative act been successful) would have been an ID object, i.e., an object that "could not exist in a world lacking beings with beliefs, desires, and intentions” (Baker, 2007, p. 11). At least this much is certainly suggested by Baker's remarks; whether it is safe to generalize from this case, however, and assume that any bonangle (were bonangles to exist) would be both a concrete physical object and an ID object is not, as it stands, settled by Baker's specification of the imagined scenario. For, based on her remarks, we do not know whether bonangles (were they to exist) must be constituted by aggregates of concrete physical objects and, if so, whether such aggregates must be pieces of driftwood or whether the reference to pieces of driftwood in Baker's scenario is merely optional, and not mandatory. Nor do we know whether bonangles (were they to exist) could be created in other ways, without calling a preexisting thing "a bonangle", and possibly even without any contribution from intentional agents at all. In a similar vein, many other important questions concerning bonangles are left open by Baker's remarks, e.g., whether bonangles (were they to exist) would be artifacts, i.e., whether, as part of their essence, they would

in question is set up to illustrate a failure of the third condition, even while the first and second conditions are satisfied.

13 For helpful discussion of Baker's bonangle-scenario, see also Evnine (2016, especially pp. 110-118). Baker's metaphysical framework more generally is discussed in Evnine (2011) and Evnine (2016, pp. 42-50). 
have an intended proper function and, if so, what this intended proper function might be, and so forth.

Given the many gaps in our understanding of what bonangles would be, were they to exist, it is certainly natural to entertain the thought that our established practices and conventions block the attempted creation of bonangles, at least in part, because of the lack of specificity in the characterization of what sorts of thing bonangles would be, were they to exist. For we might plausibly expect our existing practices and conventions to place at least minimal specificity requirements on any presumed act of creation by an intentional agent, so that it can be evaluated, on any particular occasion, whether or not the agent's creative intention had been successfully realized. Judging from Baker's reaction to the imagined scenario, however, her dissatisfaction with the bonanglescenario does not seem to revolve around the lack of specificity in the characterization of what bonangles would be, if they existed. (After all, since the scenario in question is a figment of Baker's own imagination, we might, in that case, have expected her simply to supply the missing information, if in fact the main culprit for the failed attempt to create a new primary kind was the failure to characterize with a sufficient degree of specificity what exactly was supposed to have come into existence.) Instead, Baker seems to think that, as it stands, we know enough about bonangles to conclude that the attempted creation of the new primary kind, bonangle, as described, misfires, not because of the lack of specificity in the characterization of what bonangles would be, if they existed, but for some other reason.

For the purposes at hand, let us therefore bracket questions concerning the lack of specificity in the bonangle-scenario and ask instead what Baker's reasons might be for holding that, given what we do know about bonangles, our existing practices and conventions do not support their attempted creation. In this connection, it would of course be helpful, once again, to be able to consult a theory of primary kinds, since such a theory would yield answers to questions of the form, "Under what conditions does one thing come to constitute a new entity as opposed to simply gaining a property?" (Baker, 2000, p. 41). And while, as we already noted in our earlier discussion (Section 2.2), Baker regrets not being in a position to supply such a theory of primary kinds, she does propose a characteristic by means of which to distinguish genuine cases of constitution from mere cases of property acquisition:

In the absence of a theory of primary kinds, let me suggest a consideration that would lead us to say whether a case is one of constitution or of mere property acquisition. If $\mathrm{x}$ constitutes $\mathrm{y}$, then $\mathrm{y}$ has whole classes of causal properties that $\mathrm{x}$ would not have had if $\mathrm{x}$ had not constituted anything. The anvil acquires the property of being a doorstop by our enlisting a physical property of the anvil-its 


\section{Kathrin Koslicki}

heaviness-for a special purpose: to hold open the barn door. The use of the anvil as a doorstop does not bring about instantiation of whole classes of properties that anvils per se do not have. On the other hand, David has many causal properties of different kinds that Piece would not have had if Piece had not constituted anything. And you and I have uncountably many causal properties that our bodies would not have had if they had not constituted anythingfrom looking forward to graduation, to reminding a friend to return a book, to serving on a jury, and on and on. So, even without a theory of primary kinds, we have some clear cases of constitution, and we have a characteristic - the constituted thing has different kinds of causal properties than the constituting thing would have had if it had not constituted anything-that marks off constitution from mere property acquisition.

(Baker, 2000, p. 41)

The crucial idea behind the characteristic Baker proposes here centers on the connection between constitution and the instantiation of whole classes of causal properties by the constituted thing that the constituting thing per se would not instantiate, if it did not constitute anything. ${ }^{14}$ To illustrate, let us consider a case of constitution, e.g., Piece's constituting David. In this case, according to Baker, the constituted thing, viz., David, instantiates whole classes of causal properties (e.g., properties such as causing admiration in museum-goers, fetching a high price at an art auction, etc.) that Piece would not instantiate, if it did not constitute anything. These causal properties instantiated by David, moreover, are not properties that pieces of marble per se instantiate, unless they constitute something that belongs to a primary kind (e.g., statue) distinct from their own (viz., piece of marble). In contrast, consider a case of mere property acquisition, e.g., an anvil's being used as a doorstop. In this case, Baker wants to say that the anvil acquires a new property (viz.,

14 Here it is important to remember that, according to Baker's "Constitution View", objects that stand in the constitution-relation (e.g., Piece and David) can "borrow" or "inherit" properties from each other (Section 2). Thus, while Piece constitutes David, for example, Piece also instantiates the kind property, being a statue, though it does so only contingently and derivatively, viz., by virtue of constituting an object (viz., David) that instantiates this property as its primary kind property, i.e., essentially and nonderivatively. The same sort of property inheritance also applies to other types of property (e.g., the property of causing admiration in museum-goers), which Piece may similarly "borrow" from David, while Piece constitutes David. Property inheritance, moreover, is a two-way street: that is, not only is Piece able to "borrow" properties from David but David may similarly instantiate properties derivatively (e.g., the property of being heavy), by virtue of being constituted by an object (viz., Piece) that instantiates these properties nonderivatively. (See Baker, 1999 for further discussion of bottom-up and top-down property inheritance.) 
being used as a doorstop), but it does so by enlisting properties the anvil already has to begin with (e.g., its heaviness). Furthermore, the anvil's acquisition of this new property, being used as a doorstop, does not bring about the anvil's instantiation of whole classes of causal properties that anvils per se do not instantiate. ${ }^{15}$

Applying this test to the bonangle-scenario, we may now conjecture that a case in which an intentional agent applies the newly invented word, "bonangle", to a piece of driftwood, in Baker's view, should be classified as a case of mere property acquisition, rather than as a case of constitution. For while the piece of driftwood does acquire a new property (viz., the property of being called "a bonangle"), the instantiation of this new property by the piece of driftwood proceeds by way of harnessing properties the piece of driftwood already has to begin with (e.g., in this case, perhaps nothing more than its salience to the speaker in the imagined scenario). Furthermore, the instantiation of this new property by the piece of driftwood does not by itself bring with it the instantiation of whole classes of causal properties that pieces of driftwood per se do not instantiate, without constituting something that belongs to a primary kind distinct from their own (viz., piece of driftwood). In contrast, if it were the case that, in addition to acquiring the new property of having been labeled "a bonangle", the piece of driftwood also simultaneously acquires whole classes of causal properties that pieces of driftwood per se do not instantiate, then Baker would presumably regard the recognition of a new primary kind, bonangle, as justified. In that case, it is reasonable to expect that our existing practices and conventions, in Baker's view, would no longer block, but rather support, the recognition of objects belonging to the new primary kind, bonangle, since these objects now deserve to be assigned a place in our conceptual schemes as the bearers of whole classes of causal properties. In fact, although Baker does not explicitly say so, we might further surmise that, if bonangles were associated with whole classes of causal properties, then our existing (bonangle-free) practices and conventions would be under pressure to evolve in such a way as to give rise to new practices and conventions that govern our interactions with bonangles, just as the invention of the printing press, for example, brought in its wake a whole slew of new practices and conventions surrounding our engagement with printed materials.

15 In Baker (2007, Chapter 11) and Baker (2015), the idea that constitution leads to the instantiation of whole classes of causal properties is furthermore linked up in interesting ways with other phenomena that are themselves well worth investigating, such as "ontological significance", "ontological novelty", "ontological levels", "emergence”, and "irreducibility". A discussion of these additional repercussions of Baker's proposal, however, would lead us too far afield for present purposes. 


\section{Kathrin Koslicki}

\subsection{Non-Primary to Primary Kind Transformation}

The final missing piece in our discussion of Baker's response to Zimmerman's objections is to apply Baker's proposed characteristic distinguishing cases of constitution from mere cases of property acquisition to the third type of case cited above (Section 2.3). In this case, we are presented with a scenario envisioning the transformation of a currently recognized non-primary kind, e.g., president of the United States, into a primary kind. As in the bonangle-scenario, Baker reaches a negative verdict and argues that, while perhaps not outright impossible, it is nevertheless extremely unlikely that our existing practices and conventions would evolve in such a way as to accommodate the imagined transformation of the kind, president of the United States, into a primary kind. Practices and conventions, Baker argues, are ultimately determined by human interests and, so she reasons, it is difficult to imagine that our interests surrounding the United States presidency would change in such a way as to require the recognition of objects that are fundamentally, i.e., essentially and nonderivatively, United States presidents and only contingently and derivatively persons (cf. Baker, 2007, p. 45).

According to Baker's proposed characteristic, cases of constitution differ from mere cases of property acquisition by whether an object comes to instantiate whole classes of causal properties that objects belonging to the primary kind in question do not instantiate per se, i.e., without constituting something belonging to a distinct primary kind. Applying this test to the current scenario, then, we would expect that a case in which a person, e.g., John F. Kennedy, acquires the new property, being president of the United States, is classified by Baker's criterion as a case of mere property acquisition, rather than constitution. And this prediction does in fact seem to be borne out. No doubt, John F. Kennedy, upon being inaugurated as the 35th president of the United States, also acquires many other causal properties, in addition to his taking over the United States presidency (e.g., such properties as being commanderin-chief of the United States military, exercising veto power over legislation passed by the United States congress, appointing judges to the Supreme Court, and so on). However, or so we would expect Baker to reason, these causal properties belong to property-classes (e.g., the class of legal or political properties, etc.) that persons per se can instantiate without constituting something belonging to a primary kind distinct from their own. For example, a person who has acquired the property of being a judge instantiates causal legal properties (e.g., such properties as sentencing a defendant); and a person who has acquired the property of being a United States citizen instantiates causal political properties (e.g., such properties as voting in an election). That persons per se can in fact instantiate causal properties belonging to these property-classes is of course something that cannot be simply asserted but needs to be backed 
up by further arguments. For the purposes of this discussion, however, we can reasonably grant Baker that she has provided such argument in developing a conception of persons as precisely the kinds of being who are capable of instantiating such causal properties without constituting anything that belongs to a distinct primary kind (see, e.g., Baker, 2000).

\section{Conclusion}

Over the years, Lynne Rudder Baker's practical realist framework has come under fire from critics such as Theodore Sider and Dean Zimmerman, who have wondered whether her approach in fact yields a genuinely realist metaphysics, as advertised, or merely a reflection of how our human minds represent the world. Sider, for example, suspects that it is really us, on Baker's approach, who create the world, that "continuants exist because we have concepts for them" (Sider, 2002, p. 48). And Zimmerman worries, in a similar vein, that, given Baker's conception of artifacts, it is simply too easy for intentional agents to bring new objects or new kinds of object into existence, merely by adopting new ways of thinking or speaking about existing things (Zimmerman, 2002, pp. 333-334). In her response to these objections, Baker relies crucially on the role of practices and conventions in supporting, or blocking, attempts by intentional agents to create new objects or new kinds of object. Intentional agents, in Baker's view, do have the capacity to expand our existing inventory of objects and primary kinds, and the resulting intention-dependent phenomena, she argues, should be accepted as ineliminably real. At the same time, however, as the foregoing remarks have brought out, Baker also imposes important constraints on the circumstances, and ways, in which intentional agents can bring new objects and new primary kinds into existence, not least by way of building into her account a sensitivity to the presence of causal properties that are revealed through our actual encounters with the world. As Baker writes in response to Sider's objection:

There need be no miracle. Reality doesn't 'just happen to match our conceptual scheme'. Our 'conceptual scheme' is a product of our interactions in the world. We have the conceptual scheme that we have because of our actual encounters.

(Baker, 2007, p. 46)

Even though some components of our conceptual scheme are themselves the products of our own creation, the human interests motivating these creative activities are themselves "not wholly malleable", in Baker's view: for "[w]e choose what interests to have only within a limited range" (Baker, 2007, p. 45). 


\section{Kathrin Koslicki}

\section{References}

Baker, L. R. (1999): Unity Without Identity: A New Look at Material Constitution. Midwest Studies in Philosophy, 23, 144-165

Baker, L. R. (2000): Persons and Bodies: A Constitution View. Cambridge: Cambridge University Press.

Baker, L. R. (2002): On Making Things Up: Constitution and Its Critics. Philosophical Topics: Identity and Individuation, 30, No. 1, 31-51

Baker, L. R. (2004): The Ontology of Artifacts. Philosophical Explorations, 7, No. 2, 99-111. doi: 10.1080/13869790410001694462

Baker, L. R. (2007): The Metaphysics of Everyday Life: An Essay in Practical Realism. New York, NY: Cambridge University Press.

Baker, L. R. (2009): The Metaphysics of Malfunction. Teché, 13, No. 2, 82-92.

Baker, L. R. (2015): Ontology Down-to-Earth. The Monist, 98, 145-155. doi: 10.1093/monist/onv002

Evnine, S. J. (2011): Constitution and Composition: Three Approaches to Their Relation. Protosociology, 27, 212-235

Evnine, S. J. (2016): Making Objects and Events: A Hylomorphic Theory of Artifacts, Actions, and Organisms. Oxford: Oxford University Press.

Gilbert, M. (1989): On Social Facts. New York, NY: Routledge.

Koslicki, K. (2018): Form, Matter, Substance. Oxford: Oxford University Press.

Lewis, D. (1969): Convention. Cambridge, MA: Harvard University Press.

Marmor, A. (2009): Social Conventions: From Language to Law. Princeton, NJ: Princeton University Press.

Rescorla, M. (2019): Convention. In Edward N. Zalta (Ed.) The Stanford Encyclopedia of Philosophy (Summer 2019 Edition). Retrieved from https://plato. stanford.edu/archives/sum2019/entries/convention/

Schatzki, T. R., Knorr Cetina, K., and von Savigny, E. (Eds.) (2001): The Practice Turn in Contemporary Theory. London: Routledge.

Sider, T. (2001): Four-Dimensionalism: An Ontology of Persistence and Time. Oxford: Clarendon Press.

Sider, T. (2002): Review of Persons and Bodies: A Constitution View. Journal of Philosophy, 99, 45-48.

Thomasson, A. (2003): Realism and Human Kinds. Philosophy and Phenomenological Research, 67, No. 3, 580-609.

Thomasson, A. (2007): Artifacts and Human Concepts. In Margolis, E. and Laurence, S. (Eds.) Creations of the Mind: Theories of Artifacts and Their Representation (pp. 52-73). Oxford: Oxford University Press.

Zimmerman, D. (2002): The Constitution of Persons by Bodies: A Critique of Lynne Rudder Baker's Theory of Material Constitution. Philosophical Topics: Identity and Individuation, 30, No. 1, 295-338. 